\title{
Impact of tumor-infiltrating $T$ cells on survival in patients with malignant pleural mesothelioma
}

\author{
Masaki Anraku, MD, ${ }^{a}$ Kristopher S. Cunningham, MD, PhD, ${ }^{\mathrm{b}}$ Zhihong Yun, BS, ${ }^{a}$ Ming-Sound Tsao, MD, ${ }^{\mathrm{b}}$ Li Zhang, PhD, ${ }^{\mathrm{c}}$ \\ Shaf Keshavjee, MD, ${ }^{a}$ Michael R. Johnston, MD, ${ }^{a}$ and Marc de Perrot, MD ${ }^{a}$
}

From the Division of Thoracic Surgery, Toronto General Hospital, Division of Applied Molecular Oncology, ${ }^{\mathrm{b}}$ Ontario Cancer Institute, and Division of Cellular and Molecular Biology, ${ }^{\mathrm{c}}$ Toronto General Research Institute, University Health Network, University of Toronto, Ontario, Canada.

Received for publication April 22, 2006; revisions received July 2, 2007; accepted for publication Oct 26, 2007.

Address for reprints: Marc de Perrot, MD, MSc, Toronto General Hospital 9N-961, 200 Elizabeth Street, Toronto, Ontario M5G 2C4, Canada (E-mail: marc. deperrot@uhn.on.ca).

J Thorac Cardiovasc Surg 2008;135:823-9 $0022-5223 / \$ 34.00$

Copyright (C) 2008 by The American Association for Thoracic Surgery

doi:10.1016/j.jtcvs.2007.10.026
Objective: The aim of the study was to determine the impact of tumor-infiltrating lymphocytes on survival in patients with malignant pleural mesothelioma treated with induction chemotherapy followed by extrapleural pneumonectomy.

Methods: We performed an immunohistochemical analysis of 32 extrapleural pneumonectomy specimens to assess the distribution of T-cell subtypes (CD3 ${ }^{+}, \mathrm{CD} 4^{+}$, and $\left.\mathrm{CD}^{+}\right)$, regulatory subtypes $\left(\mathrm{CD} 25^{+}\right.$and $\left.\mathrm{FOXP}^{+}\right)$, and memory subtype $\left(\mathrm{CD} 45 \mathrm{RO}^{+}\right)$within the tumor.

Results: Patients with high levels of $\mathrm{CD}^{+}$tumor-infiltrating lymphocytes demonstrated better survival than those with low levels (3-year survival: $83 \%$ vs $28 \%$; $P=.06)$. Moreover, high levels of $\mathrm{CD}^{+}$tumor-infiltrating lymphocytes were associated with a lower incidence of mediastinal node disease $(P=.004)$ and longer progression-free survival $(P=.05)$. Higher levels of $\mathrm{CD}^{+}$tumor-infiltrating lymphocytes were observed in patients treated with cisplatin and pemetrexed than in those treated with cisplatin and vinorelbine $(P=.02)$. Patients presenting high levels of $\mathrm{CD}^{+}{ }^{+}$or $\mathrm{CD}_{25} 5^{+}$tumor-infiltrating lymphocytes or low levels of $\mathrm{CD} 45 \mathrm{RO}^{+}$also demonstrated a trend toward shorter survival. However, the presence of FOXP3 ${ }^{+}$ tumor-infiltrating lymphocytes did not affect survival. After multivariate adjustment, high levels of $\mathrm{CD}^{+}$tumor-infiltrating lymphocytes remained an independent prognostic factor associated with delayed recurrence (hazard ratio $=0.38$; confidence interval $=0.09-0.87 ; P=.02$ ) and better survival (hazard ratio $=0.39$; confidence interval $=0.09-0.89 ; P=.02)$.

Conclusion: The presence of high levels of $\mathrm{CD}^{+}$tumor-infiltrating lymphocytes is associated with better prognosis in patients undergoing extrapleural pneumonectomy for malignant pleural mesothelioma. The stimulation of $\mathrm{CD}^{+}$lymphocytes can be a potential therapeutic strategy to improve outcome.

$\mathrm{M}$ alignant pleural mesothelioma (MPM) is an aggressive tumor arising from the pleura, with a poor prognosis and a median survival of 9 to 12 months from diagnosis. ${ }^{1}$ The incidence of MPM is increasing worldwide because of past exposure to asbestos in industrialized countries up to the 1970s. Multimodality therapy with chemotherapy, surgery, and hemithoracic postoperative irradiation have demonstrated some benefit in survival for highly selected patients, ${ }^{2-4}$ but the majority of cases are noncurative. Therefore, some emerging modalities, such as immunotherapy, ${ }^{5}$ intracavitary chemotherapy, ${ }^{6,7}$ and photodynamic therapy, ${ }^{8}$ have been tested to offer hope for improvement in both palliation and survival.

Clinical studies conducted during the last decade demonstrated that MPM is sensitive to immune-based therapies. Intrapleural administration of interleukin$2,{ }^{9,10}$ interferon alpha, ${ }^{11,12}$ and interferon gamma ${ }^{13}$ have had some impacts on tumor regression and decreased pleural effusion when combined with chemotherapy. The underlying pathophysiologic mechanism is complex and still largely unknown; however, the encouraging results of these immunomodulating approaches suggest that MPM is potentially immunogenic. 


\section{Abbreviations and Acronyms \\ $\mathrm{EPP}=$ extrapleural pneumonectomy \\ MPM = malignant pleural mesothelioma \\ TIL = tumor-infiltrating lymphocyte \\ TUNEL $=$ deoxyuride $-5^{\prime}$-triphosphate biotin nick end labeling}

Recent evidence suggests that the tumor microenvironment and the interaction among the tumor cells, immune cells, stromal cells, and extracellular matrix are crucial in tumor progression. ${ }^{14}$ In particular, tumor-infiltrating lymphocytes (TILs) have been recognized as principal effectors of local antitumor immune response. ${ }^{15}$ Recent studies also demonstrated the presence of regulatory lymphocytes in the tumor microenvironment that possess various functions in modulating local tumor immunity. ${ }^{16}$

The presence and role of TILs remain poorly defined in MPM. In this study, we analyzed the impact of both cytotoxic and regulatory phenotypes of TILs on survival in patients with MPM. Immunostaining with T-cell subtypes (CD3, $\mathrm{CD} 4, \mathrm{CD} 8)$, regulatory subtypes (CD25, FOXP3), and memory subtype (CD45RO) were used to select the different phenotypes within the tumors.

\section{Materials and Methods}

\section{Patients and Specimens}

Formalin-fixed, paraffin-embedded tissues were obtained from 32 patients who underwent induction chemotherapy followed by extrapleural pneumonectomy (EPP) for MPM at the Toronto General Hospital between December of 1997 and July of 2005. All tissues were collected under an institutional ethical board-approved protocol. Histopathologic diagnosis was established by our institution's pathologists. Pathologic and clinical findings were scored according to the TNM staging system proposed by the International Mesothelioma Interest Group. ${ }^{17}$ The duration of progression-free survival was the time between the surgery and the first recurrence. The recurrent disease was confirmed radiographically, cyto/histologically, or both. Overall survival was defined as the interval between the date of surgery and death, and all patients were followed up every 3 to 6 months until either their death or October $31,2006$.

\section{Histopathologic Analysis and Construction of Tissue Arrays}

All available histologic sections of tumor stained with hematoxylineosin were assessed by an investigator (M.A.) and one of our institution's pathologists (K.S.C.) for TILs. On the basis of this assessment, paraffin-embedded samples corresponding to the hematoxylineosin-stained slides were processed into tissue array blocks, which consisted of 4 cores per case with a core diameter of $1.5 \mathrm{~mm}$ using a tissue microarray instrument (Tissue Arrayer I, Beecher Instruments Inc, Sun Prairie, Wis). Tissue array blocks were then cut into $4-\mu \mathrm{m}$ sections for hematoxylin-eosin and immunohistochemical staining.

\section{Immunohistochemistry Analysis}

The antibodies used were as follows: anti-human CD3 (polyclonal; Dako, Carpinteria, Calif), anti-human CD4 (clone BC/1F6; Abcam, Cambridge, UK), anti-human CD8 (clone 4B11; Novocastra Laboratories, Ltd. Newcastle upon Tyne, UK), anti-human CD45RO (clone OPD4, Dako), anti-human CD25 (clone 4C9; Vector Laboratories, Burlingame, Calif), and anti-human FOXP3 (mAbcam22510; Abcam). Sections from the tissue array blocks were deparaffinized in xylene, washed in phosphate-buffered saline $(\mathrm{pH}$ 7.4), and rehydrated through a graded ethanol series. For anti-human CD3 antibody, the enzyme digestion method was applied with $1 \%$ pepsin in $0.01 \mathrm{~N} \mathrm{HCl}(\mathrm{pH} 2.0)$ at $37^{\circ} \mathrm{C}$ for 15 minutes. For anti-human CD8, CD25, CD45RO, and FOXP3 antibodies, deparaffinized sections were immersed into $10 \mathrm{mmol} / \mathrm{L}$ of preheated citrate buffer (pH 6.0), incubated at $95^{\circ} \mathrm{C}$ for 20 minutes, and allowed to cool to room temperature. For anti-human CD4 antibody, preheated TrisEDTA buffer ( $\mathrm{pH} 9.0$ ) was used for antigen retrieval at $95^{\circ} \mathrm{C}$ for 20 minutes. Endogenous peroxidase and biotin activities were blocked respectively using 3\% hydrogen peroxide and an avidin/biotin blocking kit (Vector Laboratories). After blocking for 15 minutes with $10 \%$ normal goat serum, sections were incubated accordingly at room temperature for either 1 hour (anti-human CD3, CD8, and CD45RO) or overnight (anti-human CD4, CD25, and FOXP3) with each primary antibody. NovaRed solution (Vector Laboratories) was applied for color development followed by counterstaining with hematoxylin. Negative control slides omitting primary antibodies were included for all experiments.

\section{Assessment of Tumor Cell Apoptosis}

To analyze the interrelationship between the presence of TILs and tumor-cell apoptosis, we performed terminal deoxyuride-5'-triphosphate biotin nick end labeling (TUNEL) on the tissue array slides. The In Situ Cell Death Detection Kit (Roche, Nutley, NJ) was used according to the manufacturer's protocol. To distinguish tumor cells from other types of cells, a double immunofluorescent staining with antihuman mesothelin antibody (clone SPM143; Abcam) was performed after TUNEL. Mesothelin is a maker for mesothelium-derived cells, including MPM. ${ }^{18}$ Slides were incubated with antihuman mesothelin antibody at room temperature for 2 hours followed by conjugation with Alexa Fluor 488 (Invitrogen, Carlsbad, Calif) as a secondary antibody. Nuclei were stained with Hoechst 33258 (Sigma, St Louis, Mo). Only cells positive for both TUNEL and antihuman mesothelin were considered as apoptotic tumor cells.

\section{Positive Cell Quantification}

Antibody stained slides were digitally scanned using Aperio ScanScope CS (Aperio Technologies, Vista, Calif), and the scanned images were analyzed with ImageScope (Aperio Technologies) for the positive cell quantification. All 4 spots of each case were evaluated for TILs, and a minimum of 4 independent areas (up to 6 areas) with the most abundant immunohistochemically positive TILs were selected at a size of $0.0625 \mathrm{~mm}^{2}$. Positive cells in the selected areas for each antibody were counted independently by 2 investigators (M.A. and Z.Y.) without knowledge of clinical information. The averages of positive TILs for each antibody were used for statistical analyses. For the apoptotic tumor-cell quantification, both TUNEL and mesothelin-positive cells were counted for all 4 spots per case 
on the tissue array slides, and the average was taken for the following analyses.

\section{Statistical Analysis}

Kaplan-Meier survival curves were used to estimate survivals on the basis of the levels of positive TILs and were compared with the log-rank test. Multivariate Cox proportional hazards models were used to calculate adjusted hazard ratios. Covariates included in the multivariate analyses were the level of $\mathrm{CD} 8^{+} \mathrm{T}$ cells (high vs low level), tumor stage (stage II vs stage III/IV), and cell type (epithelioid vs others). Cutoff values for the positive TIL counts to define subgroups were the 25 th or 50 th percentile, that is, the top 25 th or 50th percentile was defined as a high level and all others were defined as low levels. Correlation between the numbers of positive TILs and the patients' clinicopathologic factors were tested with either the $t$ test or the Wilcoxon-Mann-Whitney test, depending on the distribution of positive cell counts. The normality of the distribution of positive cell counts for each antibody was determined with the Shapiro-Wilk test (the distribution of TIL counts was judged as a normal distribution when the $P$ value was more than .05). Apoptotic tumor cell counts were analyzed in association with TIL counts and clinicopathologic factors. The chi-square test was used when categoric variables were analyzed. All analyses were performed with JMP 5.0 software (SAS Institute Inc, Cary, NC).

\section{Results}

\section{Patient Characteristics}

Patient characteristics are summarized in Table 1. There were 28 men and 4 women. The median age was 59 years (range, 21-74 years). Postoperative pathologic examination of the lymph nodes revealed $\mathrm{n} 0$ in 13 patients, $\mathrm{n} 1$ in 5 patients, $\mathrm{n} 2$ in 13 patients, and $\mathrm{n} 3$ in 1 patient. The median followup period was 35 months (range, 9-63 months). All patients received cisplatin-based induction chemotherapy followed by EPP. Postoperative hemithoracic irradiation was performed in 23 patients (72\%) with a dose ranging from 30

TABLE 1. Demographic information for patients with malignant pleural mesothelioma $(n=32)$

$$
\text { Characteristics }
$$

No.

$\begin{array}{lr}\text { TNM stage (pathologic) } & 7 \\ \text { II } & 23 \\ \text { III } & 2 \\ \text { IV } & \\ \text { Cell type } & 25 \\ \text { Epithelioid } & 1 \\ \text { Sarcomatoid } & 6 \\ \text { Mixed } & 17 \\ \text { Induction chemotherapy } & 9 \\ \text { Cisplatin + vinorelbine } & 3 \\ \text { Cisplatin + pemetrexed } & 3 \\ \text { Cisplatin + gemcitabine } & \\ \text { Cisplatin + doxorubicin } & \end{array}$

to $54 \mathrm{~Gy}$ in 21 to 30 fractions. Nine patients did not receive postoperative radical radiation.

\section{Tumor-infiltrating Lymphocytes and Clinicopathologic Factors}

The average counts of positive TILs per area for each antibody were as follows: $\mathrm{CD}^{+}$(average \pm standard deviation; $232.1 \pm 114.1), \mathrm{CD}^{+}$(119.9 \pm 94.2), $\mathrm{CD}^{+}$(73.1 \pm 40.2), $\mathrm{CD} 25^{+}$(17.5 \pm 12.6), $\mathrm{FOXP}^{+}(21.8 \pm 19.0)$, and $\mathrm{CD}^{2} 5 \mathrm{RO}^{+}(115.7 \pm 56.2)$. As shown in Figure 1, the cell counts of $\mathrm{CD}^{+}$and $\mathrm{CD} 45 \mathrm{RO}^{+}$TILs showed normal distribution (Shapiro-Wilk test; $P=.1$ and .3 ), whereas $\mathrm{CD} 4^{+}$, $\mathrm{CD}^{+}, \mathrm{CD} 25^{+}$, and $\mathrm{FOXP}^{+}$TILs did not $(P<.05)$. Representative pictures of immunohistochemical staining of TILs are shown in Figure 2.

Correlations between subtypes of TILs and lymph node metastasis were analyzed. Only the presence of $\mathrm{CD} 8^{+}$TILs significantly affected lymph node metastasis $(P=.004)$. Eight of 18 patients who had $\mathrm{n} 0$ or $\mathrm{n} 1$ disease demonstrated high levels of $\mathrm{CD}^{+}$TILs, whereas all patients with mediastinal node disease (n2 and $\mathrm{n} 3, \mathrm{n}=14$ ) showed low levels of $\mathrm{CD} 8{ }^{+}$TILs (average \pm standard deviation; $84.6 \pm 47.9$ vs $58.4 \pm 20.8$ ). The tumor samples from patients who received cisplatin/pemetrexed chemotherapy demonstrated higher levels of CD8 ${ }^{+}$TILs when compared with those from patients treated with cisplatin and vinorelbine (average \pm standard deviation; $91.4 \pm 52.4$ vs $53.4 \pm 28.6, P=.02$ ).

\section{Tumor Apoptosis and Tumor-infiltrating Lymphocytes}

Mesothelin was positive for all tumors in the current study subjects (Figure 3). The median number of both TUNEL and mesothelin double-positive cells (ie, apoptotic tumor cells) was 11.4 (range, 0-85). Significantly higher numbers of apoptotic tumor cells were observed in the tumors with high levels of $\mathrm{CD} 8^{+}$TILs compared with those with low levels $(P=.02)$. No correlations were observed between the presence of apoptotic tumor cells and other types of TILs. There was no significant difference in the numbers of apoptotic tumor cells in the tumors treated with cisplatin and pemetrexed when compared with those treated with cisplatin and vinorelbine $(P=.7)$.

\section{Prognostic Significance of Tumor-infiltrating Lymphocytes}

We hypothesized that effector subtypes of TILs would affect the prognosis favorably and that regulatory subtypes of TILs would have a negative impact. To determine the relationships between the levels of various subtypes of lymphocytes and patient prognosis, we performed both univariate and multivariate analyses.

Overall estimated 3- and 5-year survivals were 35\% and $28 \%$, respectively. The median survival for all patients was 12.2 months. Tumor recurrence was found in 17 patients 


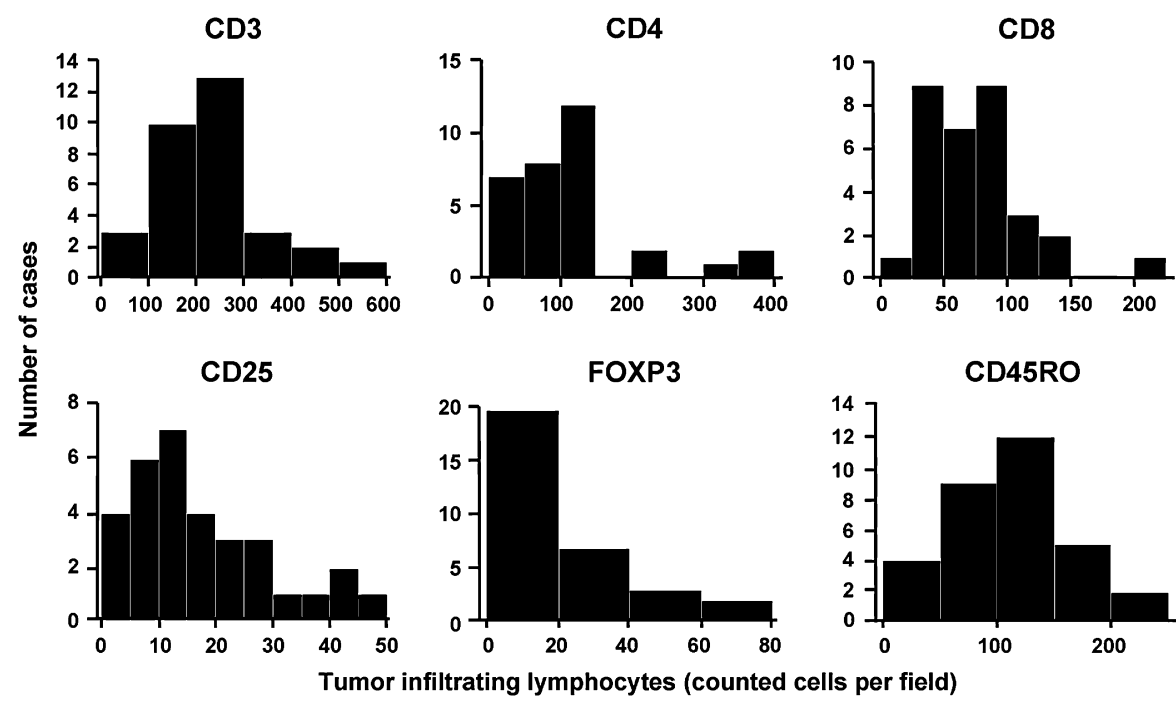

Figure 1. Frequency distributions of TILs.

$(53 \%)$ at either local $(n=6)$ or distant $(n=11)$ sites. There were 3 postoperative deaths, and these were excluded from the analyses to assess the correlation between survival and the levels of TILs. CD3 ${ }^{+}$(pan-T-cell marker) TILs were not associated with either prolonged or shortened survival $(P=.8)$. There was a clear correlation between high levels of $\mathrm{CD}^{+}$TILs and overall survival (Figure $4, A$ ), as well as progression-free survival (Figure $4, B$ ). High levels of helper TILs $\left(\mathrm{CD}^{+}\right)$and regulatory/activated TILs $\left(\mathrm{CD} 25^{+}\right)$indicated poor prognosis (3-year survival: $15 \%$ vs $53 \% ; P=$ .08 , and $17 \%$ vs $45 \% ; P=.09$, respectively; Figure $5, A$ and $B)$. No difference in survival according to the levels of FOXP3 $^{+}$TILs was observed $(P=.8$; Figure $5, C)$. High levels of CD45RO ${ }^{+}$(memory T-cell marker) TILs adversely affected survival, although the difference between the groups did not reach statistical significance $(P=.08$; Figure 5, $D)$. After multivariate adjustments, the presence of $\mathrm{CD}^{+}$TILs remained a significant prognostic factor for both prolonged progression-free survival (hazard ratio $=0.38$; 95\% confidence interval $=0.09-0.87 ; P=.02$ ) and overall survival (hazard ratio $=0.39 ; 95 \%$ confidence interval $=0.09-$ $0.89 ; P=.02$ ) (Table 2).

\section{Discussion}

Accumulating evidence suggests that TILs play an important role in mediating local tumor immunity. It has been demonstrated that $\mathrm{CD}^{+}$cytotoxic $\mathrm{T}$ cells play crucial roles in antigen-specific tumor cell killing, whereas $\mathrm{CD} 4{ }^{+} \mathrm{CD} 25^{+}$ regulatory $\mathrm{T}$ cells are key mediators of suppressing tumor immunity. ${ }^{19}$ In MPM, Leigh and Webster ${ }^{20}$ first reported the significance of lymphocytic infiltration in survival, although phenotypic analyses of lymphocytes were not performed. In their study, 33 of the 35 patients who died within 9 months of their initial presentation showed insignif- icant or absent lymphoid reaction on pretreatment biopsy specimens. In contrast, 10 of the 15 patients who survived 18 months or more demonstrated significant lymphocytic infiltration on the biopsy specimens. In the current study, we clearly observed that the presence of $\mathrm{CD} 8^{+}$TILs is a favorable sign of good clinical outcome after induction chemotherapy followed by EPP. The favorable prognostic impact of $\mathrm{CD}^{+}$TILs was confirmed by multivariate analysis with other relevant clinicopathologic factors, including cell type and tumor stage. In addition, we found that high levels of $\mathrm{CD}^{+}$TILs correlated with a low incidence of mediastinal lymph node metastases. This could be an important observation to help select candidates for EPP considering that mediastinoscopy and positron emission tomography have a low accuracy to detect nodal metastasis before EPP. ${ }^{21,22}$

Chemotherapy may alter the tumor microenvironment and increase the susceptibility to an antitumor immune response. It has been shown that chemotherapy-induced apoptotic tumor cells can potentially augment antitumor cytotoxic T-cell responses. ${ }^{23}$ In our study, we observed that the presence of TUNEL-positive apoptotic tumor cells correlated with high levels of $\mathrm{CD}^{+}$TILs. In addition, a significant correlation between induction cisplatin/pemetrexed chemotherapy and high levels of $\mathrm{CD}^{+}$TILs was also observed in our study, suggesting that this drug combination may induce greater antitumor immune responses. Because cisplatin/pemetrexed chemotherapy is the only regimen that has been shown to have a significant impact on survival in a randomized clinical trial for MPM, ${ }^{24}$ the mechanism by which the chemotherapy-induced apoptosis augments $\mathrm{CD}^{+}$T-cellmediated antitumor responses is of great interest.

In our study, we found that CD25 ${ }^{+}$TILs were negatively correlated with prognosis; however, this was not statistically significant. Regulatory $\mathrm{T}$ cells, which are characterized by 

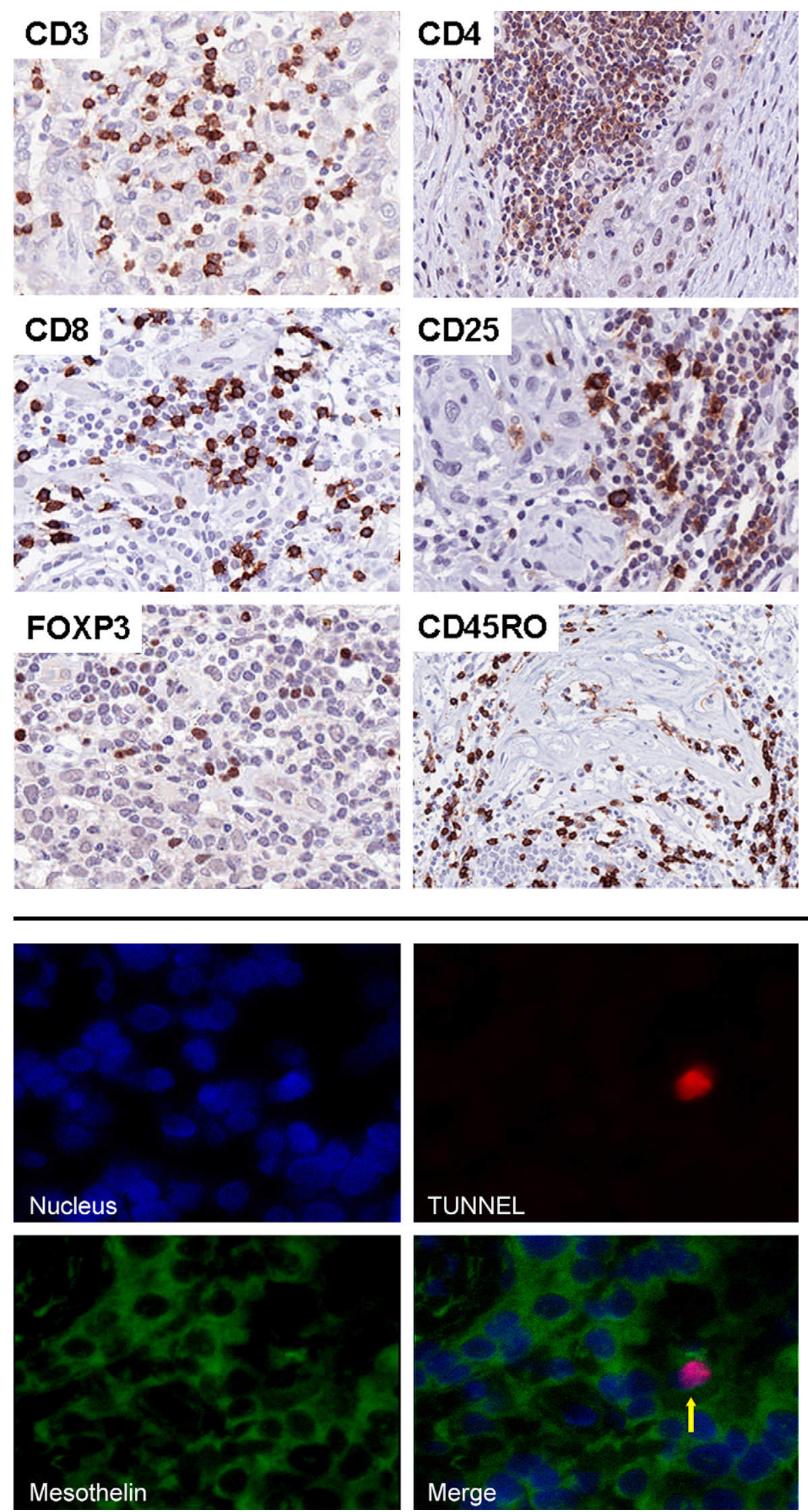

Figure 2. TILs in MPM. Magnification $\times 400$.
Figure 3. An apoptotic tumor cell (bottom right, arrow) was demonstrated as double positive for TUNEL in a nucleus (purple) and mesothelin in cytoplasm (green). Nuclei were stained with Hoechst 33258 (blue). Magnification $\times 400$. 


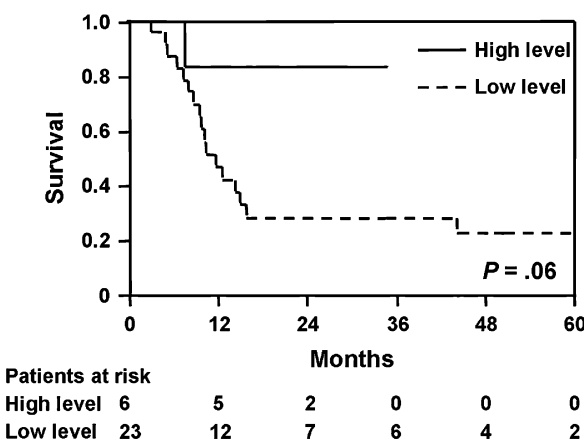

A

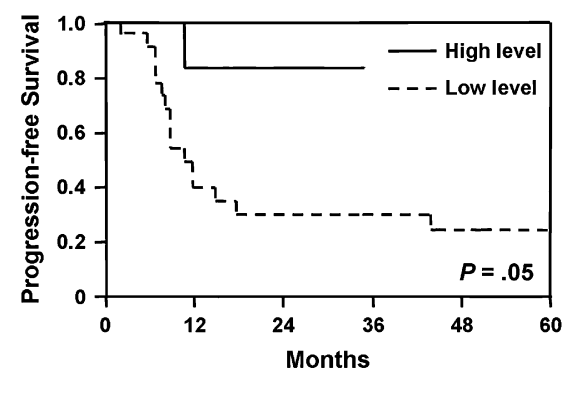

$\begin{array}{lccccc}6 & 5 & 2 & 0 & 0 & 0 \\ 23 & 10 & 7 & 6 & 4 & 2\end{array}$
Figure 4. Survival analysis for patients who underwent EPP after induction chemotherapy according to levels of CD8 $^{+}$TILs. A, Overall survival. B, Progression-free survival. the expression of both CD4 and CD25, can induce a "tumor tolerance" state by suppressing effector or helper T cells. ${ }^{19}$ Regulatory $\mathrm{T}$ cells can also impair the function of dendritic cells that are indispensable in antigen presentations to both $\mathrm{CD}^{+}{ }^{+}$helper and $\mathrm{CD}^{+}$cytotoxic T cells. On the contrary, FOXP3, a specific marker for naturally occurring regulatory $T$ cells and a crucial transcription factor that mediates the regulatory T-cell development and function, ${ }^{25}$ did not have any impact on the posttreatment prognosis of MPM. This may be partly because the numbers of lymphocytes positive for FOXP3 were small in our study. Although there are a few studies exploring the role of regulatory $\mathrm{T}$ cells in MPM, it is often not well defined because of their small sample size. ${ }^{26,27}$ Hegmans and colleagues ${ }^{26}$ demonstrated a massive influx of $\mathrm{CD} 4{ }^{+} \mathrm{CD} 25^{+} \mathrm{FOXP} 3^{+} \mathrm{T}$ cells in 4 biopsy specimens of MPM, and DeLong and colleagues ${ }^{27}$ reported fewer $\mathrm{CD} 4{ }^{+} \mathrm{CD} 25^{+}$T cells in pleural effusions from 7 patients with MPM when compared with those from patients with nonsmall cell lung cancer or breast cancer. Extended research including functional studies of TILs is required to determine the role of regulatory T cells in MPM, especially their interaction with $\mathrm{CD}^{+}$cytotoxic $\mathrm{T}$ cells.

\section{Conclusions}

Our results demonstrate that the presence of $\mathrm{CD}^{+}$TILs is associated with favorable prognosis in MPM treated with induction chemotherapy followed by EPP. Further studies are required to investigate the functional properties of effector,

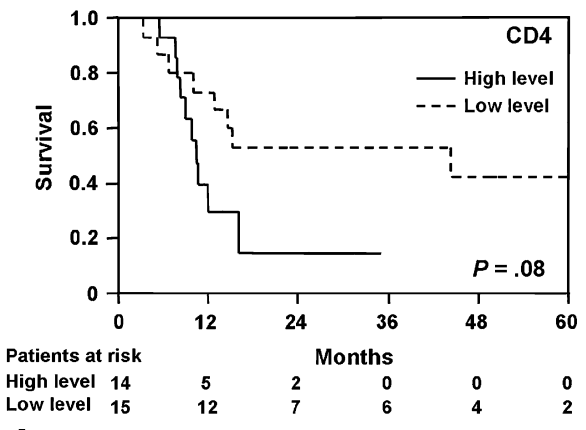

A

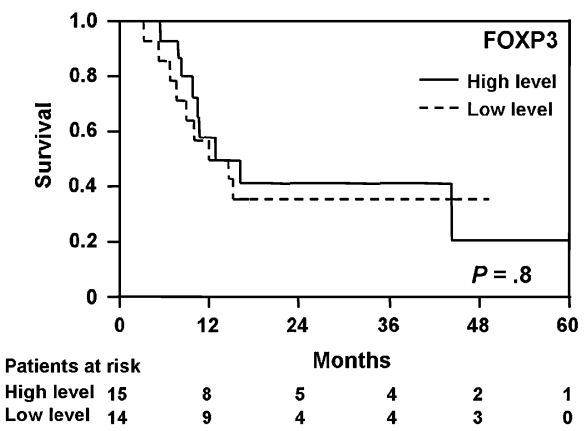

C

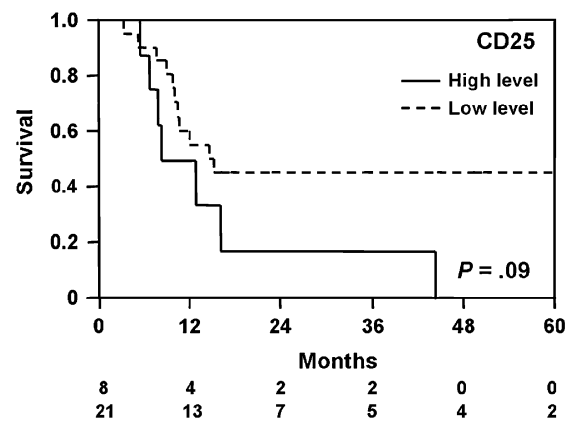

B

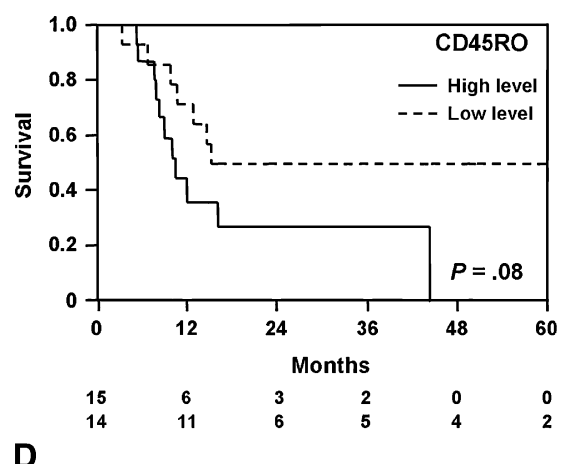

Figure 5. Survival analyses with subtypes of tumor-infiltrating lymphocytes. Overall survival according to levels of: A, CD4 ${ }^{+}$TILs; B, CD25 ${ }^{+}$TILs; C, FOXP3 ${ }^{+}$ TILs; and D, CD45RO ${ }^{+}$TILs. 
TABLE 2. Multivariate Cox proportional hazards models for disease-free and overall survivals

\begin{tabular}{|c|c|c|c|c|c|}
\hline \multirow[b]{2}{*}{ Covariate } & \multirow[b]{2}{*}{$\begin{array}{l}\text { No. of } \\
\text { patients }\end{array}$} & \multicolumn{2}{|c|}{ Progression-free survival } & \multicolumn{2}{|l|}{ Overall survival } \\
\hline & & $\begin{array}{c}\text { Hazard ratio } \\
(95 \% \mathrm{CI})\end{array}$ & $\boldsymbol{P}$ & $\begin{array}{c}\text { Hazard ratio } \\
(95 \% \mathrm{CI})\end{array}$ & $\boldsymbol{P}$ \\
\hline \multicolumn{6}{|l|}{$\mathrm{CD}^{+}{ }^{+}$TILs } \\
\hline High & 6 & $0.38(0.09-0.87)$ & .02 & $.39(0.09-0.89)$ & .02 \\
\hline Low & 23 & 1.00 & & 1.00 & \\
\hline \multicolumn{6}{|l|}{ Tumor stage } \\
\hline Stage II & 6 & $0.35(0.08-0.80)$ & .009 & $.34(0.08-0.78)$ & .01 \\
\hline $\begin{array}{l}\text { Stage III/IV } \\
\text { Cell type }\end{array}$ & 23 & 1.00 & & 1.00 & \\
\hline Epithelioid & 22 & $1.01(0.59-1.92)$ & .9 & $.98(0.59-1.91)$ & .9 \\
\hline Others & 7 & 1.00 & & 1.00 & \\
\hline
\end{tabular}

$T I L$, Tumor-infiltrating lymphocyte; $\mathrm{Cl}$, confidence interval.

helper, or regulatory phenotypes. Our findings provide a rationale for developing immunomodulating approaches to augment $\mathrm{CD} 8^{+}$cytotoxic $\mathrm{T}$ cells for both better local control and prolonged survival in MPM. In particular, MPM is naturally resistant to chemotherapy; thus, more effective treatment requires combined approaches with chemotherapy and immune-based therapies that may introduce synergistic antitumor effects. Further studies should evaluate the potential benefits of chemotherapy on antitumor immune responses to incorporate immune-based approaches into the current treatment strategy.

We thank Kelvin So for expert assistance with the immunohistochemical stainings.

\section{References}

1. Robinson BW, Musk AW, Lake RA. Malignant mesothelioma. Lancet. 2005;366:397-408.

2. Sugarbaker DJ, Flores RM, Jaklitsch MT, Richards WG, Strauss GM, Corson JM, et al. Resection margins, extrapleural nodal status, and cell type determine postoperative long-term survival in trimodality therapy of malignant pleural mesothelioma: results in 183 patients. J Thorac Cardiovasc Surg. 1999;117:54-65.

3. Weder W, Kestenholz P, Taverna C, Bodis S, Lardinois D, Jerman M, et al. Neoadjuvant chemotherapy followed by extrapleural pneumonectomy in malignant pleural mesothelioma. J Clin Oncol. 2004;22:3451-7.

4. Flores RM. Induction chemotherapy, extrapleural pneumonectomy, and radiotherapy in the treatment of malignant pleural mesothelioma: the Memorial Sloan-Kettering experience. Lung Cancer. 2005;49(Suppl 1): S71-4.

5. Berghmans T, Paesmans M, Lalami Y, Louviaux I, Luce S, Mascaux C, et al. Activity of chemotherapy and immunotherapy on malignant mesothelioma: a systematic review of the literature with meta-analysis. Lung Cancer. 2002;38:111-21.

6. Lu C, Perez-Soler R, Piperdi B, Walsh GL, Swisher SG, Smythe WR, et al. Phase II study of a liposome-entrapped cisplatin analog (LNDDP) administered intrapleurally and pathologic response rates in patients with malignant pleural mesothelioma. J Clin Oncol. 2005;23: 3495-501.

7. Richards WG, Zellos L, Bueno R, Jaklitsch MT, Janne PA, Chirieac LR, et al. Phase I to II study of pleurectomy/decortication and intraoperative intracavitary hyperthermic cisplatin lavage for mesothelioma. J Clin Oncol. 2006;24:1561-7.

8. Friedberg JS, Mick R, Stevenson J, Metz J, Zhu T, Buyske J, et al. A phase I study of Foscan-mediated photodynamic therapy and surgery in patients with mesothelioma. Ann Thorac Surg. 2003;75:952-9.

9. Astoul P, Picat-Joossen D, Viallat JR, Boutin C. Intrapleural administration of interleukin-2 for the treatment of patients with malignant pleural mesothelioma: a Phase II study. Cancer. 1998;83:2099-104.

10. Castagneto B, Zai S, Mutti L, Lazzaro A, Ridolfi R, Piccolini E, et al. Palliative and therapeutic activity of IL-2 immunotherapy in unresectable malignant pleural mesothelioma with pleural effusion: results of a phase II study on 31 consecutive patients. Lung Cancer. 2001;31: 303-10.

11. Soulie P, Ruffie P, Trandafir L, Monnet I, Tardivon A, Terrier P, et al. Combined systemic chemoimmunotherapy in advanced diffuse malignant mesothelioma. Report of a phase I-II study of weekly cisplatin/ interferon alfa-2a. J Clin Oncol. 1996;14:878-85.

12. Parra HS, Tixi L, Latteri F, Bretti S, Alloisio M, Gravina A, et al. Combined regimen of cisplatin, doxorubicin, and alpha- $2 \mathrm{~b}$ interferon in the treatment of advanced malignant pleural mesothelioma: a Phase II multicenter trial of the Italian Group on Rare Tumors (GITR) and the Italian Lung Cancer Task Force (FONICAP). Cancer. 2001;92: 650-6.

13. Monnet I, Breau JL, Moro D, Lena H, Eymard JC, Menard O, et al. Intrapleural infusion of activated macrophages and gamma-interferon in malignant pleural mesothelioma: a phase II study. Chest. 2002;121:1921-7.

14. Zou W. Immunosuppressive networks in the tumour environment and their therapeutic relevance. Nat Rev Cancer. 2005;5:263-74.

15. Yu P, Fu YX. Tumor-infiltrating T lymphocytes: friends or foes? Lab Invest. 2006;86:231-45.

16. Curiel TJ, Coukos G, Zou L, Alvarez X, Cheng P, Mottram P, et al. Specific recruitment of regulatory $T$ cells in ovarian carcinoma fosters immune privilege and predicts reduced survival. Nat Med. 2004;10: 942-9.

17. Rusch VW. A proposed new international TNM staging system for malignant pleural mesothelioma. From the International Mesothelioma Interest Group. Chest. 1995;108:1122-8.

18. Ordonez NG. Application of mesothelin immunostaining in tumor diagnosis. Am J Surg Pathol. 2003;27:1418-28.

19. Zou W. Regulatory T cells, tumour immunity and immunotherapy. Nat Rev Immunol. 2006;6:295-307.

20. Leigh RA, Webster I. Lymphocytic infiltration of pleural mesothelioma and its significance for survival. S Afr Med J. 1982;61:1007-9.

21. Flores RM, Akhurst T, Gonen M, Larson SM, Rusch VW. Positron emission tomography defines metastatic disease but not locoregional disease in patients with malignant pleural mesothelioma. $J$ Thorac Cardiovasc Surg. 2003;126:11-6.

22. de Perrot M, Uy K, Anraku M, Tsao MS, Darling G, Waddell TK, et al. Impact of lymph node metastasis on outcome after extrapleural pneumonectomy for malignant pleural mesothelioma. $J$ Thorac Cardiovasc Surg. 2007;133:111-6.

23. Nowak AK, Lake RA, Marzo AL, Scott B, Heath WR, Collins EJ, et al. Induction of tumor cell apoptosis in vivo increases tumor antigen crosspresentation, cross-priming rather than cross-tolerizing host tumorspecific CD8 T cells. J Immunol. 2003;170:4905-13.

24. Vogelzang NJ, Rusthoven JJ, Symanowski J, Denham C, Kaukel E, Ruffie P, et al. Phase III study of pemetrexed in combination with cisplatin versus cisplatin alone in patients with malignant pleural mesothelioma. J Clin Oncol. 2003;21:2636-44.

25. Fontenot JD, Gavin MA, Rudensky AY. Foxp3 programs the development and function of CD4+CD25+ regulatory T cells. Nat Immunol. 2003;4:330-6

26. Hegmans JP, Hemmes A, Hammad H, Boon L, Hoogsteden HC, Lambrecht BN. Mesothelioma environment comprises cytokines and T-regulatory cells that suppress immune responses. Eur Respir J. 2006;27:1086-95.

27. DeLong P, Carroll RG, Henry AC, Tanaka T, Ahmad S, Leibowitz MS, et al. Regulatory $\mathrm{T}$ cells and cytokines in malignant pleural effusions secondary to mesothelioma and carcinoma. Cancer Biol Ther. 2005;4:342-6. 